\title{
A child with atopic features, raised serum IgE, and recurrent infection treated with levamisole
}

\author{
L BUSINCO, F LAURENTI, P ROSSI, E GALLI, AND F AIUTI
}

Department of Paediatrics I, Clinical Immunology Division, and Department of Internal Medicine, Section of Infectious Diseases, University of Rome, Italy

SUMmary. A 6-year-old girl had a long history of severe eczema, asthma, recurrent otitis media, and staphylococcal infections with disseminated chronic skin abscesses. Immunological studies showed a neutrophil chemotaxis defect, hyperimmunoglobulinaemia E, IgE antibodies against cows' milk proteins, absence of IgM, and absence of staphylococcal haemolysins. Neutrophil phagocytic and bactericidal functions and complement system were normal. In the course of treatment with levamisole $(2.5 \mathrm{mg} / \mathrm{kg}, 3$ times a week for one year) a striking clinical improvement occurred: the skin lesions and the staphylococcal abscesses gradually cleared and the girl gained weight. There was also a partial correction of the immune deficiency.

In 1966 Davis et al. ${ }^{1}$ reported two children aged 9 and 6 years with long histories of chronic staphylococcal abscesses and chronic dermatitis, which they termed Job's syndrome. Several clinically similar disorders with hyperimmunoglobulinaemia $\mathrm{E}$, and abnormal leucocyte mobility have since been described. ${ }^{2-6}$ Treatment with levamisole has improved the clinical and immunological conditions of a few such patients. ${ }^{7-8}$

We report a 6-year-old girl who, from age 2 months, has suffered from severe eczema, recurrent staphylococcal infections, and widespread chronic abscesses. Laboratory findings included defect of cellular neutrophil chemotaxis, high plasma IgE level, pronounced eosinophilia, a T-lymphocyte dysfunction, and an IgM deficiency. Treatment with levamisole for one year $(2.5 \mathrm{mg} / \mathrm{kg}$ three times a week) resulted in clinical improvement, with a partial correction of the immunological defects.

\section{Case report}

A 6-year-old girl, the second child of related parents, was admitted to hospital in May 1977. Her mother suffers from allergic rhinitis and bronchial asthma with strikingly positive skin tests and specific IgE to Dermatophagoides pteronyssinus and to house dust; no history of recurrent infection was reported by the rest of the family. The patient began to suffer from severe eczema and bronchial asthma when she was 2 months old. At 12 months she developed recurrent upper and lower respiratory infections, staphylo- coccal sepsis, middle-ear infections, and 'cold' skin abscesses. She was repeatedly admitted to hospitals; cultures obtained from ear discharge and from subcutaneous abscesses grew Staphylococcal aureus on several occasions.

At age 5 she developed chronic herpetic keratitis, and mucosal and cutaneous candidiasis. $\mathrm{H}_{1}$ receptors, antihistamines, steroids, and antifungal treatments had no effect. A milk-free and egg-free diet given over a long period proved unsuccessful.

In May 1977 she was referred to our unit. On admission she appeared very ill: her temperature was up to $39^{\circ} \mathrm{C}$, weight and height were on the $3 \mathrm{rd}$ centile. The skin was reddened with diffuse lichenification and pruritus; the nails were dystrophic and thickened. Large cold abscesses were present on the back, in the axillae and on the legs, with enlarged lymph nodes in the cervical, axillary, and inguinal regions. There was a corneal ulcer in the left eye, and purulent conjunctivitis in both eyes. Chest $x$-ray films showed a large infiltration of the left lower lobe.

Repeated blood counts including platelets were normal except for a persistent eosinophilia, of between 30 and $50 \%\left(4 \cdot 2-6 \cdot 0 \times 10^{9} / 1\right)$. The blood group was AB. Blood cultures grew a penicillinresistant $S$. aureus and intravenous gentamicin $7 \mathrm{mg} / \mathrm{kg}$ was given. The staphylococcal sepsis and pneumonia resolved within 2 weeks.

Cellular immunity. Skin tests for delayed hypersensitivity were performed with the following: 
dermatophytin ' $O$ ' 1:10 (Hollister-Stier), streptokinase-streptodornase 40 units (Lederle), purified protein derivative (PPD) 5 UI (Sclavo). The sites were examined after 24 hours and again at 48 hours, and the reaction was graded as positive if there was an induration of at least $6 \mathrm{~mm}$.

Lymphocytes were isolated by Ficoll-Hypaque gradient centrifugation and adjusted to a final concentration of $10^{6}$ lymphocytes $/ \mathrm{ml}$. The E-rosetteforming lymphocytes were evaluated by the method of Jondal et al., ${ }^{9}$ counting 200 cells. In vitro response of lymphocytes to phytohaemagglutinin (PHA) was detected by the method of Park and Good ${ }^{10}$ using $0.1 \mathrm{ml}$ lymphocytes at a concentration of $5 \times 10^{5} \mathrm{ml}$ in RPMI 1640. The leucocyte inhibition test was performed by the method of Federlin et al. ${ }^{11}$ using as antigens Candida albicans and PHA (normal values $<85 \%$ ).

Humoral immunity. B-lymphocytes were identified by the method of Pernis et al. ${ }^{12}$ Serum immunoglobulins and complement fraction were estimated by radial immunodiffusion using a standard technique (Boering Werke). Immunoglobulins $\mathrm{E}$ were measured by the Prist method, and specific IgE antibodies to cows' milk, house dust, D. pteronyssinus, Lolium, and Alternaria tenuis were measured by the Phadebas radioallergosorbent test. Staphylococcal haemolytic titre, and Schick test were performed by standard techniques.

Inflammatory response. Preparation of a suspension of granulocytes was as reported previously. ${ }^{13}$ The nitroblue tetrazolium (NBT) dye test was performed by the plate method of Balducci et al..$^{14}$ The bactericidal test was that of Quie et al. ${ }^{15}$ using $S$. aureus $502 \mathrm{~A}$ as the test strain; results were expressed as the percentage of bacteria still alive after 120 minutes of incubation with neutrophils. Opsonisation, phagocytosis, and candidacidal activity were estimated microscopically by a method previously described. ${ }^{16}$ The myeloperoxidase was assessed by Kaplow's colouration. ${ }^{17}$ Leucocyte adherence was tested by the method of MacGregor et al.,18 and chemotaxis as previously reported. ${ }^{19}$

All the immunological tests were performed several times-before, during, and after treatment with levamisole.

\section{Results}

Specific immunity. Serum immunoglobulins IgA and IgG were respectively 187 and $2380 \mathrm{mg} / 100 \mathrm{ml}$; serum IgM and staphylococcal haemolysins were consistently absent in repeated tests. Schick test, after three injections of diphtheria toxoid, was negative. Total and specific IgE against cows' milk were greatly raised: $16000 \mathrm{U} / \mathrm{ml}$ and $49 \mathrm{PRU} / \mathrm{ml}$ respectively. Ig-bearing lymphocytes were: $\operatorname{IgG} 7$, $\operatorname{IgA} 2$, and $\operatorname{IgM} 7 \%$.

Delayed hypersensitivity responses to candida, SK-SD, and PPD were absent. Circulating T-lymphocytes were persistently low $\left(12 \%, 204 / \mathrm{mm}^{3}\right)$ and the in vitro lymphocyte response to PHA was depressed (stimulatory index, 6); the inhibition of leucocyte migration with candida antigen (1:10, $1: 100,1: 1000$ ) was respectively 25,22 , and $26 \%$ of normal, according to our laboratory standards. All the immunological tests were repeated several times on different days.

Inflammatory responses. Total haemolytic complement, C3, C4, C3PA, serum opsonic activity, phagocytic, and bactericidal ability of the patient's neutrophils against $S$. aureus, myeloperoxidase content, and NBT test were all normal.

In vitro studies of chemotaxis showed a severe defect in the migration of the patient's granulocytes. In several tests performed before treatment, the cellular chemotactic response was only $5 \%$ that of the age control group, while the humoral generation of chemotactic factors was normal $(80 \%)$.

Clinical and immunological findings after treatment. The high levels of specific IgE antibodies to cows' milk prompted us to continue a milk-free diet for 3 months. During this period the immunological tests and the clinical conditions remained unchanged.

After this observation period, levamisole was started at a dose of $2.5 \mathrm{mg} / \mathrm{kg}$ orally 3 times a week for one year. No side effects were observed during this time. The cows' milk-free diet was continued. After 2 months there was a pronounced clinical improvement; the dermatitis gradually cleared up, and the recurrent infections and skin abscesses became less and less frequent and eventually disappeared. A partial correction of the immunological defect could also be observed (Table).

T-lymphocyte count increased; the blastogenic response to PHA became normal; and delayed skin test to candida became positive; the motile response of neutrophils became normal. Total and specific IgE decreased, while serum IgM and staphylococcal haemolysin remained undetectable.

After one year of treatment with levamisole, this medication was stopped while maintaining the eggfree and milk-free diet. Now, after two years without levamisole, the clinical and immunological improvements continue, the girl's clinical condition is good and she attends school regularly. 
Table Immunological data before, during, and after levamisole treatment

\begin{tabular}{|c|c|c|c|c|}
\hline & $\begin{array}{l}\text { Normal } \\
\text { values } \\
(\text { mean } \pm \text { SD) }\end{array}$ & Before & During* & After \\
\hline Cellular chemotaxis & $100 \pm 18$ & 5 & 85 & 90 \\
\hline Random motility & $100 \pm 15$ & 5 & 85 & 110 \\
\hline Total IgE $(\mathrm{U} / \mathrm{ml})$ & $18 \pm 3$ & 16000 & 8000 & 1570 \\
\hline Specific IgE cows' milk (PRU/ml) & - & 49 & 20 & 10 \\
\hline IgM (mg/100 ml) & $65 \pm 25$ & Undetectable & Undetectable & Undetectable \\
\hline Staphylococcal haemolitic titre $(\mathrm{U} / \mathrm{ml})$ & - & Undetectable & Undetectable & Undetectable \\
\hline T-lymphocytes $(\%)$ & $61 \pm 5$ & 12 & 43 & 50 \\
\hline T-lymphocytes $\left(\times 10^{9} / 1\right)$ & $>1.5$ & $0 \cdot 204$ & 0.86 & $1 \cdot 2$ \\
\hline In vitro lymphocyte response to PHA SI & $>10$ & 6 & 14 & 30 \\
\hline
\end{tabular}

SI $=$ stimulatory index. ${ }^{*} 2$ months of treatment.

\section{Discussion}

The clinical findings in this patient were similar to those of the children with cellular chemotaxis defect associated with hyperimmunoglobulinaemia $\mathrm{E}$ reported by a number of authors. ${ }^{4-5} 20-21$ Recurrent severe staphylococcal infections and eczematous dermatitis are signs that are typical of this disease. In our patient however, the immunological abnormalities differed from those of the cases reported. In addition to the accepted abnormalities (high IgE levels, neutrophil chemotaxis defect, T-lymphocyte dysfunction) there was consistent IgM deficiency, not described before. Furthermore, despite repeated infections with $S$. aureus the child lacked staphylococcal haemolysins.

A primary specific response defect to $S$. aureus would explain the high susceptibility to such infections. Schopfer et al. ${ }^{22}$ found IgE antistaphylococcal antibodies in 7 affected patients and they suggested that 'the recurrent, atypical staphylococcal infections are not due to a primary defect of polymorphonuclear function, as measured by chemotaxis, but may be a consequence of an abnormal immunologic response to $S$. aureus'. They did not refer to the presence of specific agglutinins. It is likely that in our patient the lack of IgM might have been the primary defect predisposing to recurrent infections and to atopic symptoms, as in other immunoglobulin deficiencies. ${ }^{23}$ The allergic conditions could have induced the neutrophils and T-lymphocyte dysfunctions.

The mechanism underlying the neutrophil and T-lymphocyte dysfunction in this syndrome is still a matter for discussion. Hill and Quie ${ }^{5}$ showed that neutrophil chemotaxis can be inhibited in vitro by histamine, probably through the increase of the intracellular concentration of cyclic-AMP, and that the IgE-mediated histamine release in their patients might be one aetiology for the decreased chemotactic responsiveness. ${ }^{520}{ }_{24-25}$ In patients suffering from allergic rhinitis the migration defect was present only during periods of active rhinitis; it was also possible to induce it in vitro by incubating the patient's leucocytes with the appropriate allergen. ${ }^{26}$ Further support for this suggestion is provided by the in vitro improvement of chemotaxis by $\mathrm{H}_{2}$-receptor antagonist. ${ }^{21}$

There is strong evidence that histamine could lower the number and the function of circulating $T$ lymphocytes ${ }^{27}$ as shown also in allergic patients. ${ }^{28-29}$ A persuasive hypothesis put forward by Busse and Sosman $^{30}$ is that the 'coldness' of abscesses might be related to high histamine levels. They showed that histamine inhibits the release of $\beta$-glycuronidase in a dose-dependent manner; this inhibition was paralleled by an increase in neutrophil cyclic-AMP level.

Levamisole has been reported to decrease cyclicAMP and to increase cyclic-GMP level in human and animal lymphocytes and, by maintaining intracellular cyclic-GMP concentration, to enhance microtubular assembly and polymorphonuclear motility. ${ }^{831-34}$

Levamisole treatment in our patient brought the chemotactic responsiveness back to normal, and increased the number and function of peripheral T-lymphocytes. The disappearance of recurrent infections and skin abscesses after treatment with levamisole may have been attributable to the partial correction of the immunological defect.

The striking improvement of the dermatitis suggests that the abnormal function of the immune system may be crucial for the pathogenesis of the eczema. In support of such a hypothesis is the observation that the eczema in 2 patients with the Wiskott-Aldrich syndrome receiving a bone-marrow transplant disappeared after the engraftment of $T$ lymphocytes, suggesting that the recipient's abnormal T-lymphocyte function was the cause of the eczema. ${ }^{35}$

In conclusion, we consider that levamisole may be useful in patients suffering from severe recurrent infections associated with defective neutrophil chemotaxis and hyperimmunoglobulinaemia $\mathrm{E}$, although allergen-avoidance may also be required.

This study was supported by a National Research Council grant. 


\section{References}

1 Davis S D, Schaller J, Wedgwood R J. Job's syndrome. Recurrent 'cold' staphylococcal abscesses. Lancet 1966; i: $1013-5$.

2 Blum R, Geller G, Fish L A. Recurrent severe staphylococcal infections, eczematoid rash, extreme elevation of IgE, eosinophilia, and divergent chemotactic responses in two generations. J Pediatr 1977; 90: 607-9.

3 Buckley R H, Wray B B, Belmaker E Z. Extreme hyperimmunoglobulinemia $E$ and undue susceptibility to infection. Pediatrics 1972; 49: 59-70.

4 Church J A, Frenkel L D, Wright D G, Bellanti J A. $T$ lymphocyte dysfunction, hyperimmunoglobulinemia $\mathrm{E}$, recurrent bacterial infections, and defective neutrophil chemotaxis in a negro child. $J$ Pediatr 1976; 88: 982-5.

5 Hill H R, Quie P G. Raised serum IgE levels and defective neutrophil chemotaxis in three children with recurrent bacterial infections. Lancet 1974; ii: 183-7.

- Pabst H F, Holmes B, Quie P G, Gerurz H, Rodey G, Good R A. A case of Job's syndrome: clinical and immunological investigation (abstract). Pediatr Res 1971, 5: 380 .

7 De Cree J, Emmery L, Timmermans J, Eeckels R, De Cock W, Verhaegen H. Defective neutrophil chemotaxis and raised serum IgE levels in a child with recurrent bacterial infections and eczema. Arch Dis Child 1978; 53: 144-9.

8 Hogan N A, Hill H R. Enhancement of neutrophil chemotaxis and alteration of levels of cellular cyclic nucleotides by levamisole. J Infect Dis 1978; 138: 437-44.

9 Jondal M, Holm G, Wigzell H. Surface markers on human $T$ and $B$ lymphocytes: a large population of lymphocytes forming non-immune rosettes with sheep red blood cells. J Exp Med 1972; 136: 207-15.

10 Park B H, Good R A. A new micromethod for evaluating lymphocyte responses to phytohemagglutinin: quantitative analysis of the function of thymus dependent cells. Proc Natl Acad Sci USA 1972; 69: 371-3.

11 Federlin K, Maini R N, Russel A S, Dumonde D C. A micro method for peripheral leukocyte migration in tuberculin sensitivity. J Clin Pathol 1971; 24: 533-6.

12 Pernis B, Forni L, Amante L. Immunoglobulin spots on the surface of rabbit lymphocytes. J Exp Med 1970; 132: 1001-18.

13 Solberg C O. Enhanced susceptibility to infections. A new method for the evaluation of neutrophil granulocyte functions. Acta Pathol Microbiol Scand 1972; 80B: 10-18.

14 Balducci L, Battaglia M, Midulla M. Prova diagnostica rapida per la granulomatosi cronica. Boll Soc Ital Biol Sper 1975; 51 : 499-504.

15 Quie P G, White J G, Holmes B, Good R A. In vitro bactericidal capacity of human polymorphonuclear leukocytes: diminished activity in chronic granulomatous disease of childhood. J Clin Invest 1967; 46: 668-79.

16 Laurenti F, Battaglia M, Lendvai D, Midulla M, Rezza E. Micrometodo semplificato per la determinazione dell' attività candidacida dei leucociti. Ann Sclavo 1976; 18: 574-84.

17 Kaplow L S. Simplified myeloperoxidase stain using benzidine dihydrocloride. Blood 1965; 26: 215-9.

18 MacGregor R R, Spagnuolo P J, Lentnek A L. Inhibition of granulocyte adherence by ethanol, prednisone, and aspirin measured with an assay system. $N$ Engl J Med 1974; 291 : 642-6.

19 Laurenti F, Businco L, Barbato M B, Palermo D, Rossini M, Rezza E. Difetto familiare di chemiotassi associato a deficit di IgM: effetti clinici ed immunologici del levamisolo. Riv Ital Pediatr 1978; 4: 571-8.
20 Hill H R, Estensen R D, Hogan M A, Quie P G. Severe staphylococcal disease associated with allergic manifestations, hyperimmunoglobulinemia $\mathrm{E}$, and defective neutrophil chemotaxis. J Lab Clin Med 1976; 88: 796-806.

21 Hill H R, Williams P B, Krueger G G, Janis B. Recurrent staphylococcal abscesses with defective neutrophil chemotaxis and allergic rhinitis. Ann Intern Med 1976; 85: 39-43.

22 Schopfer K, Baerlocher K, Price P, Krech U, Quie P G, Douglas S D. Staphylococcal IgE antibodies, hyperimmunoglobulinemia $\mathrm{E}$, and Staphylococcus aureus infections. $N$ Engl J Med 1979; 300: 835-8.

23 Soothill J F, Stokes C R, Turner M W, Norman A P, Taylor B. Predisposing factors and the development of reaginic allergy in infancy. Clin Allergy 1976; 6: 305-19.

24 Bourne H R, Lichtenstein L N, Melmon K L, Henney C S, Weinstein Y, Shearer G M. Modulation of inflammation and immunity by cyclic AMP. Science 1974; 184: 19-28.

25 Rivkin I, Becker E L. Possible implication of cyclic $3^{\prime}-5^{\prime}$ adenosine monophospate in the chemotaxis of rabbit peritoneal polymorphonuclear leukocytes (abstract). Fed Proc 1972; 31 : 657.

26 Rubin J L, Griffiths R W, Hill H R. Allergen-induced depression of neutrophil chemotaxis in allergic individuals. $J$ Allergy Clin Immunol 1978; 62: 301-8.

27 Koopman W J, Gillis M H, Davis J R. Prevention of MIF activity by agents known to increase cellular cyclic AMP. $J$ Immunol 1973; 110: 1609-14.

28 De Cock W, De Cree J, Verhaegen H. Restoration by levamisole of histamine inhibited $E$ rosette formation of $T$ lymphocyte of patients with allergies. Int Arch Allergy Appl Immunol 1977; 54: 176-82.

29 Galli E, Rossi P, Businco E, Perlini R, Businco L. Rosette $\mathrm{E}$ ed istamina. Comportamento delle rosette $\mathrm{E}$ dopo incubazione con istamina e durante la stagione di pollinazione in soggetti pollinosici. Effetto del levamisolo. Folia Allergy Immunol Clin 1979; 26: 173-7.

30 Busse W W, Sosman J. Histamine inhibition of neutrophil lysosomal enzyme release: an $\mathbf{H}_{2}$ histamine receptor response. Science 1976; 194: 737-8.

31 Anderson R, Glover A, Koornhof H J, Rabson P. In vitro stimulation of neutrophil motility by levamisole: maintenance of GMPc levels in chemotactically stimulated levamisole treated neutrophils. J Immunol 1976; 117: 428-32.

32 Hadden J, Coffey P G, Hadden E M, Lopez-Corrales E, Sunshine G H. Effects of levamisole and imidazole on lymphocyte proliferation and cyclic nucleotide levels. Cell Immunol 1975; 20: 98-103.

33 Verhaegen H, De Cree J, De Cock W, Verbruggen F. Restoration by levamisole of low-rosette forming cells in patients suffering from various diseases. Clin Exp Immunol 1977; 27: 313-8.

34 Wright D G, Kirkpatrick C H, Gallin J I. Effects of levamisole on normal and abnormal leukocyte locomotion. J Clin Invest 1977; 59: 941-50.

35 Parkman R, Rappeport J, Geha R, et al. Complete correction of the Wiskott-Aldrich syndrome by allogenic bone marrow transplantation. N Engl J Med 1978; 298: 921-7.

Correspondence to Professor Luisa Businco, Department of Paediatrics, University of Rome, Viale Regina Elena 324, 00161 Rome, Italy.

Received 9 October 1979. 